\title{
Análisis y determinación del criterio que utiliza el SAT para determinar la tasa de IVA aplicable a la venta o distribución de cacahuate industrializado destinado al consumo humano
}

Analysis and determination of the criteria used by the SAT to determine the VAT rate applicable to the sale or distribution of industrialized peanuts for human consumption

\section{Araiza Santillán Marisa Aideé ${ }^{1 凶}$, Castillo Mata Patricia ${ }^{1}$, Torres López Octavio ${ }^{1}$, Segovia Mendoza Nubia Iveth ${ }^{1}$, García Soto Gerardo ${ }^{2}$ \\ ${ }^{1}$ Universidad Autónoma de Chihuahua, Facultad de Contaduría y Administración. Calle 6a y ave 21 poniente sector poniente s/n Delicias, Chihuahua. ${ }^{2}$ Tecnológico Nacional de México, Instituto} Tecnológico de Delicias.

${ }^{凶}$ Autor para correspondencia: maraiza28@yahoo.com.mx

Recibido: $15 / 04 / 2019$

Aceptado: 15/05/2019

\section{RESUMEN}

El siguiente informe describe la situación que atravesaron las personas físicas con actividad empresarial régimen general de Delicias Chihuahua cuyo giro fue orientado a la venta o distribución de cacahuate industrializado respecto a la tasa de IVA que optaron aplicar al enajenar su producto. Para generar la información se realizaron encuestas a contribuyentes que venden y facturan cacahuate industrializado para poder determinar el fundamento que motivo su decisión y posteriormente se tabularon los resultados obtenidos. Los resultados obtenidos de las encuestas que se aplicaron al tamaño de muestra, evidencia que existen 2 tasas de IVA que se aplican en la venta o distribución de cacahuate industrializado, $0 \%$ y $16 \%$. Más del $70 \%$ de los contribuyentes que se encuestados mostraron preferencia por la aplicación del $0 \%$ a la venta de cacahuate industrializado, argumentando que lo consideran como un producto designado a la alimentación. Dicha preferencia la han sostenido preferentemente por periodos mayores a un año y menores a cinco años. La decisión de no es sustentada bajo ningún argumento.

Palabras clave: Producto, Impuesto, Valor, Agregado.

\begin{abstract}
The following report describes the situation experienced by individuals with business activity as a general regime of Delicias Chihuahua, whose turn was oriented towards the sale or distribution of industrialized peanuts with respect to the VAT rate that they chose to apply when selling their product. To generate the information, surveys were carried out to taxpayers who sell and invoice industrialized peanuts in order to determine the basis for their decision and subsequently tabulated the results obtained. The results
\end{abstract}


obtained from the surveys that were applied to the sample size, evidence that there are 2 VAT rates that are applied in the sale or distribution of industrialized peanuts, $0 \%$ and $16 \%$. More than $70 \%$ of the taxpayers that were surveyed showed preference for applying $0 \%$ to the sale of industrialized peanuts, arguing that they consider it as a product designated for food. This preference has been maintained preferably for periods of more than one year and less than five years. The decision is not supported under any argument.

Keywords: Product, Tax, Value, Added.

\section{INTRODUCCIÓN}

En México, la Ley del impuesto al valor agregado fue publicada en el Diario Oficial de la Federación, el día 29 de diciembre de 1979 y entró en vigor en toda la República, el día 1o. de enero de 1980.

Hasta la fecha, el IVA nunca fue percibido por el fisco directamente, sino por el vendedor al momento de la realización de cualquier transacción comercial (es decir, es un impuesto al consumo). Dichas características lo hicieron un impuesto muy atractivo para el fisco, ya que su evasión es difícil y la recaudación simple. (Garcia Gomez, 2016).Este impuesto es pagado cuando se realizan actos o actividades gravados por la Ley del Impuesto al Valor Agregado.

El siguiente informe describe la situación que atravesaron las personas físicas con actividad empresarial régimen general de Delicias Chihuahua cuyo giro fue orientado a la venta o distribución de cacahuate industrializado respecto a la tasa de IVA que optaron aplicar al enajenar su producto.

El objetivo primordial fue ofrecer a los contribuyentes un sustento fiscal que pudiera ser usado en su beneficio, respecto a la tasa de IVA aplicable, sin que este fuera objeto de evasión fiscal, entendiéndose por esto el que una persona infringiendo la ley deje de pagar dolosamente, toda o una parte de algún impuesto a cargo. (ElConta.com, 2010).

El empleo de determinada tasa de IVA en la venta o distribución de cacahuate industrializado para consumo humano puede representar para el comerciante ser competitivo en el mercado y por ende determinar el éxito o el fracaso de un negocio.

Esta investigación no solo otorgara información específicamente a este sector de contribuyentes, podrá servir de base a otros regímenes que lleven a cabo operaciones afines.

\section{MATERIALES Y MÉTODOS}

Para generar la información se realizaron encuestas a contribuyentes que venden y facturan cacahuate industrializado para poder determinar el fundamento que motivo su decisión y posteriormente se tabularon los resultados obtenidos.

El tamaño de muestra fue 100 contribuyentes $(\mathrm{n}=100)$. Las preguntas de la encuesta fueron seleccionadas para que generen información precisa de la situación en torno a la venta o distribución de cacahuate industrializado. 
Tabla 1. Encuesta que se aplicó a los contribuyentes es la siguiente.

\begin{tabular}{|c|c|}
\hline Pregunta & Opción de respuestas \\
\hline $\begin{array}{l}\text { Tasa de IVA aplicada en la venta de cacahuate } \\
\text { industrializado. } \\
\text { ¿Qué tasa de IVA aplica en la emisión de sus facturas? }\end{array}$ & $\begin{array}{l}-0 \% \\
-16 \%\end{array}$ \\
\hline $\begin{array}{l}\text { Lapso de tiempo de aplicación de tasa. } \\
\text { ¿Durante cuánto tiempo ha aplicado la tasa } 0 \% \text { y } 16 \% \text { ? }\end{array}$ & $\begin{array}{l}\text {-Menor a } 1 \text { año } \\
-1 \text { a } 5 \text { años } \\
\text {-Más de } 5 \text { años }\end{array}$ \\
\hline $\begin{array}{l}\text { Motivo por el que se aplica la tasa del } 0 \% \text { y } 16 \% \text { de IVA. } \\
\text { ¿Cuál es el motivo por el que aplica la tasa del } 0 \% \text { o } 16 \% \\
\text { de IVA? }\end{array}$ & $\begin{array}{l}\text {-Producto destinado a la } \\
\text { alimentación. } \\
\text { - Alimento preparado. } \\
\text { - Vegetal industrializado. } \\
\text {-Se desconoce. }\end{array}$ \\
\hline $\begin{array}{l}\text { Influencia de contribuyentes afines al giro. } \\
\text { ¿Antes de aplicar la tasa de su elección consulto la } \\
\text { opinión de una persona que realiza su misma actividad? }\end{array}$ & $\begin{array}{l}\text {-Contribuyentes con tasa } 0 \% \\
\text { - Contribuyentes con tasa } 16 \% \\
\text { - Total de contribuyentes. }\end{array}$ \\
\hline $\begin{array}{l}\text { Actos de molestia por parte de la autoridad. } \\
\text { ¿Ha sido objeto de algún acto de molestia por parte de la } \\
\text { autoridad al utilizar la tasa de su elección? }\end{array}$ & $\begin{array}{l}-\mathrm{Si} \\
-\mathrm{No}\end{array}$ \\
\hline $\begin{array}{l}\text { Repercusiones de la aplicación de la tasa } 0 \% \text { de IVA. } \\
\text { ¿Cuáles considera que son las repercusiones de aplicar la } \\
\text { tasa 0\% de IVA? }\end{array}$ & $\begin{array}{l}\text {-Obtención de saldos a favor de } \\
\text { IVA. } \\
\text {-Perder competitividad en } \\
\text { precios. } \\
\text {-Evitar conflictos con la } \\
\text { autoridad. } \\
\text {-Desembolsar menos impuestos. } \\
\text {-Perdida de liquidez. } \\
\text {-Las desconoce. }\end{array}$ \\
\hline $\begin{array}{l}\text { Repercusiones de la aplicación de la tasa } 16 \% \text { de IVA. } \\
\text { ¿Cuáles considera que son las repercusiones de aplicar la } \\
\text { tasa } 16 \% \text { de IVA? }\end{array}$ & $\begin{array}{l}\text {-Obtención de saldos a favor de } \\
\text { IVA. } \\
\text { - Perder competitividad en } \\
\text { precios. } \\
\text {-Evitar conflictos con la } \\
\text { autoridad. } \\
\text {-Desembolsar menos impuestos. } \\
\text {-Perdida de liquidez. } \\
\text {-Las desconoce. }\end{array}$ \\
\hline
\end{tabular}




\begin{tabular}{|l|l|}
\hline $\begin{array}{l}\text { Información adicional a la Ley del IVA que funde su } \\
\text { decisión. }\end{array}$ & $\begin{array}{l}\text {-Contribuyentes con tasa } 0 \% \\
\text { ¿Cuenta usted con información adicional a la Ley del }\end{array}$ \\
IVA para fundamentar su decisión? & $\begin{array}{l}\text {-Contribuyentes con tasa } 16 \% \\
\text {-Total de contribuyentes. }\end{array}$ \\
\hline $\begin{array}{l}\text { Información adicional motiva cambio de decisión. } \\
\text { ¿Contar con información adicional motivaría que Ud. } \\
\text { cambiará su decisión respecto a la tasa de IVA que } \\
\text { aplica? }\end{array}$ & -Contribuyentes con tasa 0\% \\
\hline
\end{tabular}

\section{RESULTADOS Y DISCUSIÓN}

Los resultados obtenidos de las encuestas que se aplicaron al tamaño de muestra, evidencia que existen 2 tasas de IVA que se aplican en la venta o distribución de cacahuate industrializado, $0 \%$ y $16 \%$. Más del $70 \%$ de los contribuyentes que se encuestados mostraron preferencia por la aplicación del $0 \%$ a la venta de cacahuate industrializado, argumentando que lo consideran como un producto designado a la alimentación, sin embargo es importante que conozcan cuáles son los actos a los que son sujetos a la tasa preferencial del $0 \%$, esta información se encuentra referida en la Ley del IVA (Lechuga Santillan, Ley del IVA, 2017).

Dicha preferencia la han sostenido preferentemente por periodos mayores a un año y menores a cinco años. La decisión de no es sustentada bajo ningún argumento, tal situación es preocupante tomando en consideración que desde el 2014 a la Reforma Fiscal se le dieron varias modificaciones, como por ejemplos que "Toda persona, ya sea física o moral, estudiante, empresario, profesionista u obrero, debe conocer el Impuesto al Valor Agregado (IVA), cuya tasa general es del 16\%; sin embargo, también existe una tasa preferente del $0 \%$, y es importante estar al tanto de los casos en los que aplica y en los que no" (SoyConta, 2014).
Las repercusiones mencionadas por los contribuyentes por si decisión de aplicar la tasa del $0 \%$ son variadas, sin embargo las más recurrentes son solventar menos impuestos y la obtención de saldos a favor del IVA.

\section{CONCLUSIONES}

El criterio que la autoridad utiliza es considerar la venta o distribución de cacahuate industrializado a la tasa general de $16 \%$ de IVA ya que, al estar industrializado, no reúne los requisitos establecidos en el criterio 11/IVA/N para ser considerado como producto destinado a la alimentación.

Los contribuyentes necesitan recibir asesoría e información adicional de LIVA para fundamentar sus decisiones y verse beneficiados preferentemente.

\section{LITERATURA CITADA}

ElConta.com. (2010). ElConta.com. Recuperado el 20 de 10 de 2017, de ElConta.com: http://elconta.com/2010/06/07/diferenci a-entre-evasion-y-elusion-fiscal/

García Gómez, A. (2016). CIEP. Recuperado el 20 de 10 de 2017, de CIEP: 
http://ciep.mx/isr-e-iva-evoluciones-

historicas/

Lechuga Santillan, E. (2017). Reglamento de la

Ley del IVA. En E. Lechuga Santillan,

FISCO AGENDA 2017 (pág. 3). Mexico
DF: EDICIONES FISCALES ISEF SA.

SoyConta. (2014). SoyConta.com. Recuperado el 20 de 10 de 2017, de SoyConta.com: http://www.soyconta.mx/en-queproductos-o-servicios-aplica-la-tasa-del$\underline{\text { 0-del-iva/ }}$

Copyright (c) 2019 Marisa Aideé Araiza Santillán, Patricia Castillo Mata, Octavio Torres López, Nubia Iveth S egovia Mendoza y G erardo Garcia Soto

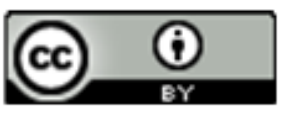

Este texto está protegido por una licencia licencia CreativeCommons 4.0.

Usted es libre para Compartir — copiar y redistribuir el material en cualquier medio o formato-y Adaptar el documento — remezclar, transformar y crear a partir del material- para cualquier propósito, incluso para fines com erciales, siempre que cumpla la condición de:

Atribución: Usted debe dar crédito a la obra original de manera adecuada, proporcionar un enlace a la licencia, e indicar si se han realizado cambios. Puede hacerlo en cualquier forma razonable, pero no de forma tal que sugiera que tiene el apoyo del licenciante o lo recibe por el uso que hace de la obra.

Resumendelicencia - Textocompletodelalicencia 